\title{
Lipid peroxidation during myocardial ischaemia induced by pacing
}

\author{
K G Oldroyd, M Chopra, A C Rankin, J J F Belch, S M Cobbe
}

\begin{abstract}
Oxygen derived free radical generation can be shown in experimental models of myocardial ischaemia and reperfusion and may cause cellular damage by peroxidising polyunsaturated membrane phospholipids. An attempt was made to quantify human intracardiac lipid peroxidation during transient myocardial ischaemia by measuring the aortic and coronary sinus concentrations of malondialdehyde (a marker of lipid peroxidation) before, during, and after incremental pacing. Twenty six patients were paced until they had severe chest pain or $2 \mathrm{~mm}$ ST segment depression or they reached a paced rate of 180 beats/ min. They were divided into two groups according to whether or not lactate was produced during pacing. Twelve patients (group 1), all with coronary artery disease, produced myocardial lactate during pacing. None of the other 14 patients (group 2), half of whom had coronary disease, produced lactate during pacing. Concentrations of malondialdehyde in the aorta and coronary sinus were significantly higher in group 1 than in group 2. Five minutes after the end of pacing coronary sinus malondialdehyde concentrations in group 1 had increased significantly from baseline values. There were no changes with time in the coronary sinus concentration of malondialdehyde in group 2 or in the aorta in either group. The negative malondialdehyde extraction ratio in group 1 suggests that intracardiac lipid peroxidation occurs during transient human myocardial ischaemia.
\end{abstract}

Electron paramagnetic resonance spectroscopy was used to provide direct evidence of oxygen derived free radical formation after coronary artery ligation in open chested dogs, but this involves the intracoronary infusion of a spin trap, in this case, $\alpha$-phenyl $N$-tert-butyl nitrone and has not as yet been performed in humans. ${ }^{1}$ The evidence implicating free radicals in the myocardial cell damage associated with myocardial ischaemia and particularly reperfusion is conflicting and rests largely on the results of studies of the use of various radical scavenging agents in animal models. ${ }^{23}$ The enzyme superoxide dismutase, which scavenges free radicals, was shown to reduce infarct size in a canine model of coronary artery occlusion/reperfusion, ${ }^{4}$ though this effect could not be reproduced by another group using a similar model..$^{5}$ Allopurinol, an inhibitor of the enzyme xanthine oxidase, which helps to generate free radicals, has been used in similar studies with the same conflicting results. ${ }^{67} \mathrm{~A}$ problem common to all of this work is the difficulty of confirming an equal degree of ischaemia in each of the different treatment groups. Ambrosio et al tried to avoid this difficulty by quantifying the ischaemic insult using ${ }^{31} \mathrm{P}$ magnetic resonance spectroscopy to measure continuously myocardial phosphate content and intracellular $\mathrm{pH}$. They were able to show that recombinant human superoxide dismutase accelerates the biochemical and functional recovery in isolated rabbit hearts subjected to periods of global ischaemia.

Most animal models of ischaemia/reperfusion used periods of total global ischaemia. It is not known whether brief ischaemic insults without complete cessation of nutrient flow, such as occur during episodes of angina pectoris, also result in the generation of cytotoxic free radicals. As indicated above, direct measurement of the chemical moieties implicated (superoxide anion, hydroxyl radical) is difficult owing to their extremely short half lives. Free radical attack, however, causes the oxidative degradation of polyunsaturated lipids in cell and lysosomal membranes. ${ }^{910}$ Among the products of this age and sex related lipid peroxidation, ${ }^{11}$ various cytotoxic aldehydes have been characterised and shown to be, by themselves, capable of inducing changes within biological membranes. ${ }^{12} 13$ One of these, malondialdehyde, can be measured in human plasma. We therefore measured concentrations of malondialdehyde and lactate in the aorta and coronary sinus before, during, and immediately after incremental cardiac pacing in patients with and without coronary artery disease.

\section{Patients and methods}

PATIENT SELECTION

We studied 26 patients ( 19 men) aged $42-68$ undergoing cardiac catheterisation for the evaluation of chest pain. Patients with recently unstable angina were excluded. All drug treatment was continued until 24 hours before the study. Thereafter only sublingual nitrates were prescribed. Written informed consent was obtained from each subject and the study was approved by the ethics committee of Glasgow Royal Infirmary. 
STUDY PROTOCOL

Patients fasted overnight and were sedated with diazepam (10 $\mathrm{mg}$ orally). Under local anaesthesia, disposable catheters were placed in the coronary sinus (via the left basilic vein) and the descending aorta (via the right femoral artery). A temporary pacing wire was placed in the right atrial appendage via the right femoral vein. The position of the coronary sinus catheter was confirmed by injecting a small amount of contrast medium. Arterial blood pressure and 12 electrocardiographic leads were monitored continuously throughout the study. Samples of arterial and coronary sinus blood were taken simultaneously to measure lactate and malondialdehyde.

The heart was then paced at just above the resting sinus rate and the rate was increased by 10 beats/minute every two minutes until the development of severe chest pain, $2 \mathrm{~mm} \mathrm{ST}$ segment depression, or a paced rate of 180 beats/minute. If atrioventricular block developed before an end point was reached, the pacing wire was repositioned in the right ventricular apex and the study continued. Repeat arterial and coronary sinus blood samples were obtained at the peak pacing rate and at 30 seconds and five minutes (cases 10-26 only) after the end of pacing.

Individual variations in coronary venous anatomy, catheter placement, and the extent and pattern of coronary artery disease mean that biochemical changes in the coronary sinus effluent do not always reflect continuing myocardial ischaemia. ${ }^{14}$ In an attempt to minimise this sampling error, and particularly in a study designed to show biochemical evidence of reperfusion injury, we decided to regard the response to incremental pacing as positive only when there was evidence of frank lactate production (that is, lactate concentration in the coronary sinus was higher than in the aorta). We used frank lactate production as the marker of an ischaemic response so that we could be as certain as possible that the sampling catheter was indeed draining an ischaemic area of myocardium.

\section{ASSAYS}

Lactate was measured by a commercially available enzymatic assay (Boehringer Diagnostica). Malondialdehyde was measured by the technique of Santos et al. ${ }^{15}$ Plasma was separated immediately after each pacing study and all samples were assayed in duplicate on the same day. The mean intra and inter assay coefficients of variation in our laboratory are $5 \cdot 0 \%$ and $7 \cdot 7 \%$ respectively.

\section{STATISTICAL ANALYSIS}

The distribution of the data derived from this study was assessed by calculating the standardised skewness and kurtosis of each of the variables. Group concentrations are expressed as medians (inter-quartile range) for non-parametric data or means (SEM) for parametric data. Two tailed group comparisons were made by Wilcoxon signed rank and Mann-Whitney tests or Student's $t$ test for paired and unpaired data as appropriate. Extraction ratios were calculated in the conventional manner from concentrations in the aorta and coronary sinus.

$$
\frac{\text { Aorta }- \text { coronary sinus }}{\text { Aorta }} \times 100 \%
$$

\section{Results}

\section{LACTATE EXTRACTION AND CORONARY ARTERY} DISEASE

During pacing, myocardial lactate production developed or increased in 12 patients (group 1). The lactate extraction ratio, even at baseline, was significantly less in group 1 than in group 2 (lactate extractors): $+18 \%(-7$ to +29$) v$ $+40 \%(+25$ to +45$), 2 \mathrm{p}=0.01$. Despite the exclusion of patients with unstable or recently unstable angina, three patients in group 1 showed biochemical evidence of ischaemia at rest. By definition, all of the group 1 patients were producing lactate at peak pacing rate, while all 14 patients in group 2 continued to have a positive extraction ratio: $-28 \%$ ( -70 to $-11) v+16 \%$ ( +10 to +30$)$.

Tables 1 and 2 summarise the clinical and anatomical characteristics of the patients in both groups. The groups were comparable for age and sex (mean ages, $56 v 54$; men, 8/12 $v 10 /$ 14). All 12 patients in group 1 had obstructive coronary artery disease, including in 10 patients a stenosis of at least $50 \%$ (diameter) in the left anterior descending artery. Patients 6 and 7 did not have disease of the left anterior descending artery but did develop evidence of ischaemia in the anterolateral leads during exercise and pacing. In half of the patients in group 2, the results of coronary angiography

Table 1 Clinical and anatomical characteristics of lactate producers (group 1)

\begin{tabular}{|c|c|c|c|c|c|c|c|c|}
\hline \multirow[b]{2}{*}{ Case no } & \multirow[b]{2}{*}{ Age } & \multirow[b]{2}{*}{ Sex } & \multirow[b]{2}{*}{ Treatment } & \multirow{2}{*}{$\begin{array}{l}\text { Peak paced heart } \\
\text { rate (beats/min) }\end{array}$} & \multicolumn{2}{|c|}{$S T$ depression $(\geqslant 1.0 \mathrm{~mm})$} & \multirow[b]{2}{*}{$C A D$} & \multirow[b]{2}{*}{ Left ventricle } \\
\hline & & & & & Exercise & Pacing & & \\
\hline $\begin{array}{r}1 \\
2 \\
3 \\
4 \\
5 \\
6 \\
7 \\
8 \\
9 \\
10 \\
11 \\
12\end{array}$ & $\begin{array}{l}60 \\
52 \\
51 \\
57 \\
60 \\
64 \\
60 \\
58 \\
64 \\
43 \\
59 \\
53\end{array}$ & $\begin{array}{l}\mathbf{M} \\
\mathbf{M} \\
\mathbf{M} \\
\mathbf{M} \\
\mathbf{F} \\
\mathbf{M} \\
\mathbf{M} \\
\mathbf{M} \\
\mathbf{F} \\
\mathbf{M} \\
\mathbf{F} \\
\mathbf{M}\end{array}$ & $\begin{array}{l}\text { Ca, nitrate } \\
\text { BB, Ca, nitrate } \\
\text { BB, Ca, Asp } \\
\text { Nil } \\
\text { BB, Ca, Asp } \\
\text { BB, Ca, Asp } \\
\text { BB } \\
\text { BB, nitrate } \\
\text { BB } \\
\text { BB, Ca, nitrate } \\
\text { BB, Ca, nitrate } \\
\text { BB, nitrate }\end{array}$ & $\begin{array}{l}180 \\
130 \\
110 \\
170 \\
170 \\
120 \\
140 \\
150 \\
150 \\
170 \\
150 \\
160\end{array}$ & $\begin{array}{l}\text { II, III, aVF, V4-6 } \\
\text { V3-5 } \\
\text { II, III, aVF, V4-6 } \\
\text { V2-5 } \\
\text { II, III, aVF, V4-6 } \\
\text { V2-6 } \\
\text { I, II, aVL, V4-6 } \\
\text { V2-4 } \\
\text { I, aVL, V2-6 } \\
\text { V1-4 } \\
\text { I, aVL, V2-6 } \\
\text { II, III, aVF, V3-5 }\end{array}$ & $\begin{array}{l}\text { II, III, aVF, V4-6 } \\
\text { V3-6 } \\
\text { II, III, aVF, V4-6 } \\
\text { V2-6 } \\
\text { II, III, aVF, V4-6 } \\
\text { V2-6 } \\
\text { I, II, aVL, V4-6 } \\
\text { V2-4 } \\
\text { I, aVL, V3-6 } \\
\text { V1-4 } \\
\text { I, aVL, V2-6 } \\
\text { II, III, aVF, V4-6 }\end{array}$ & $\begin{array}{l}\text { 3VD } \\
\text { 3VD } \\
\text { 3VD } \\
\text { LAD } \\
\text { LAD } \\
\text { RCA } \\
\text { RCA, Cx } \\
\text { 3VD } \\
\text { 3VD } \\
\text { LAD } \\
\text { LAD, RCA } \\
\text { LAD, Cx }\end{array}$ & $\begin{array}{l}\text { Abnormal } \\
\text { Normal } \\
\text { Abnormal } \\
\text { Normal } \\
\text { Normal } \\
\text { Normal } \\
\text { Normal } \\
\text { Abnormal } \\
\text { Normal } \\
\text { Normal } \\
\text { Abnormal } \\
\text { Normal }\end{array}$ \\
\hline
\end{tabular}

CAD, coronary artery disease ( $\geqslant 50^{\circ}$ o diameter stenosis); $3 \mathrm{VD}, 3$ vessel disease; LAD, left anterior descending; RCA, right coronary artery; Cx, circumflex; Ca, calcium antagonist; $\mathrm{BB}, \boldsymbol{\beta}$ blocker; Asp, aspirin. 
Table 2 Clinical and anatomical characteristics of lactate extractors (group 2)

\begin{tabular}{|c|c|c|c|c|c|c|c|c|}
\hline \multirow[b]{2}{*}{ Case no } & \multirow[b]{2}{*}{ Age } & \multirow[b]{2}{*}{ Sex } & \multirow[b]{2}{*}{ Treatment } & \multirow{2}{*}{$\begin{array}{l}\text { Peak paced } \\
\text { heart rate }\end{array}$} & \multicolumn{2}{|c|}{$S T$ depression ( $\geqslant 1.0 \mathrm{~mm}$ ) } & \multirow[b]{2}{*}{$C A D$} & \multirow[b]{2}{*}{ Left ventricle } \\
\hline & & & & & Exercise & Pacing & & \\
\hline $\begin{array}{r}1 \\
2 \\
3 \\
4 \\
5 \\
6 \\
7 \\
8 \\
9 \\
10 \\
11 \\
12 \\
13 \\
14\end{array}$ & $\begin{array}{l}61 \\
49 \\
49 \\
51 \\
51 \\
47 \\
53 \\
50 \\
50 \\
65 \\
63 \\
55 \\
68 \\
53\end{array}$ & $\begin{array}{l}M \\
F \\
M \\
F \\
M \\
F \\
M \\
F \\
M \\
M \\
M \\
M \\
M \\
M\end{array}$ & $\begin{array}{l}\text { BB, nitrate, Asp } \\
\text { Nil } \\
\text { Nil } \\
\text { BB, nitrate } \\
\text { BB, Ca, nitrate } \\
\text { Nil } \\
\mathrm{Ca} \text {, Asp } \\
\mathrm{Ca} \text {, nitrate } \\
\text { BB } \\
\mathrm{Ca} \text {, nitrate } \\
\mathrm{Nil} \\
\mathrm{BB} \text {, nitrate } \\
\mathrm{BB} \text {, nitrate } \\
\mathrm{BB}, \text { nitrate, Asp }\end{array}$ & $\begin{array}{l}140 \\
160 \\
150 \\
150 \\
120 \\
180 \\
140 \\
160 \\
160 \\
150 \\
160 \\
180 \\
150 \\
170\end{array}$ & $\begin{array}{l}\text { I, II, aVL, V2-6 } \\
\text { II, III, aVF, V4-6 } \\
\text { I, aVL, V5-6 } \\
\text { Nil } \\
\text { II, III, aVF, V4-6 } \\
\text { Nil } \\
\text { Nil } \\
\text { Nil } \\
\text { Nil } \\
\text { II, III, aVF, V3-6 } \\
\text { V2-5 } \\
\text { Nil } \\
\text { II, III, aVF, V5-6 } \\
\text { Nil }\end{array}$ & $\begin{array}{l}\text { I, II, aVL, V2-6 } \\
\text { V2-6 } \\
\text { V5-6 } \\
\text { II, III, aVF, V3-5 } \\
\text { II, III, aVF, V5-6 } \\
\text { II, III, aVF, V3-6 } \\
\text { Nil } \\
\text { Nil } \\
\text { Nil } \\
\text { I, II, V4-6 } \\
\text { I, aVL, V3-6 } \\
\text { Nil } \\
\text { V3-6 } \\
\text { Nil }\end{array}$ & $\begin{array}{l}\text { 3VD } \\
\text { Nil } \\
\text { 3VD } \\
\text { Nil } \\
\text { 3VD } \\
\text { Nil } \\
\text { Nil } \\
\text { Nil } \\
\text { Nil } \\
\text { 3VD } \\
\text { Nil } \\
\text { LAD, RCA } \\
\text { 3VD } \\
\text { 3VD }\end{array}$ & $\begin{array}{l}\text { Normal } \\
\text { Normal } \\
\text { Abnormal } \\
\text { Normal } \\
\text { Normal } \\
\text { Normal } \\
\text { Normal } \\
\text { Normal } \\
\text { Normal } \\
\text { Normal } \\
\text { Normal } \\
\text { Abnormal } \\
\text { Normal } \\
\text { Abnormal }\end{array}$ \\
\hline
\end{tabular}

were normal. The other seven had coronary artery disease; in all seven there were major lesions in dominant right coronary arteries. In two of these seven patients there was no electrical evidence of ischaemia on exercise or pacing. Four of the other five showed ischaemia only in the inferior or inferolateral leads. The venous drainage from the myocardium supplied by the right coronary artery usually drains into the proximal coronary sinus, and in patients with rate-limiting right coronary artery stenoses the sampling catheter may not accurately reflect ischaemia in the territory of the right coronary artery. ${ }^{14}$ This may partly account for our failure to detect lactate production in these seven patients. The only patient in group 2 who had coronary disease and electrical evidence of anterior ischaemia during pacing (patient $1, S T$ depression $>1 \mathrm{~mm}$ in leads I, II, aVL, V2-6) had complete occlusion of the right coronary artery.

\section{PLASMA CONCENTRATIONS OF}

\section{MALONDIALDEHYDE DURING PACING}

Malondialdehyde concentrations before pacing, like the basal lactate extraction, were significantly higher in group 1 (lactate producers) than in group 2 (lactate extractors) in both the aorta and coronary sinus (table 3). The values in group 1 but not in group 2 were significantly higher than the peripheral venous blood concentrations in a group of 16 normal subjects $(18.5(1.4) \mu \mathrm{mol} / \mathrm{l}: 2 \mathrm{p}=0.004 v$ aorta, $2 \mathrm{p}=0.006 v$ coronary sinus). At all three subsequent sampling times, except in the aorta 5 minutes after pacing, this difference was maintained. Additionally, 5 minutes after pacing there was a significant increase in coronary sinus concentrations in group 1 after the end of pacing compared with baseline (fig 1). In contrast, there were no significant changes with time in the coronary sinus concentrations in group 2 or in the aorta in either group. This resulted in the generation of a negative malondialdehyde extraction ratio 5 minutes after pacing in group 1 that differed significantly from the positive ratio present in group 2 at the same time (fig 2).

\section{Discussion}

Incremental pacing to provoke myocardial ischaemia in resting patients with coronary artery disease partly avoids the complicating and unpredictable systemic metabolic effects of exercise stress. ${ }^{16}$ Because pacing produces regional rather than global ischaemia, however, problems remain with the assessment of biochemical changes in ischaemic myocardium by sampling of the coronary effluent. Thus large changes in the ischaemic area may be masked by the diluting effect of venous effluent from non-ischaemic areas. ${ }^{14}{ }^{17}$ We chose to sample 30 seconds after the end of pacing because this is the time of maximum washout of toxic ischaemic metabolites from the myocardium..$^{18}$ The sample taken 5 minutes after pacing was added to try to identify lipid peroxidation occurring as a result of continuing reoxygenation of the previously ischaemic heart.

There are several potential sources of oxygen derived free radicals during human myocardial ischaemia/repérfusion. Ischaemia itself may produce cytotoxic free radicals as a result of reactions involving mitochondrial electron transfer ${ }^{19}$ or after catecholamine degradation by monoamine oxidases, auto-oxidation or, what is more likely at physiological $\mathrm{pH}$, metal catalysed oxidation. ${ }^{20} 21$ The univalent reduction of oxygen by activated neutrophils, though an important source of radicals ${ }^{2022}$ is probably not relevant in transient ischaemia, because it is likely that the chemotactic factors required to promote neutrophil migration into ischaemic tissue require several hours for full expression. $^{23}$ In separate studies, we found no

Table 3 Plasma concentrations of malondialdehyde during pacing ( $\mu$ mol/l)

\begin{tabular}{|c|c|c|c|c|c|c|}
\hline & \multicolumn{3}{|l|}{ Aorta } & \multicolumn{3}{|c|}{ Coronary sinus } \\
\hline & Group 1 & Group 2 & $95 \% \mathrm{CI} \dagger$ & Group 1 & Group 2 & $95^{\circ}{ }_{\circ} \mathrm{CI}$ \\
\hline $\begin{array}{l}\text { Baseline } \\
\text { Peak heart rate } \\
30 \text { s post pacing } \\
5 \text { min post pacing }\end{array}$ & $\begin{array}{l}26 \cdot 2(1.9)^{\star} \\
26 \cdot 0(1.9)^{\star} \\
25 \cdot 4(1.5)^{\star} \\
26 \cdot 6(2 \cdot 4)\end{array}$ & $\begin{array}{l}20 \cdot 4(1 \cdot 8) \\
20 \cdot 4(1 \cdot 7) \\
20 \cdot 2(1 \cdot 5) \\
23 \cdot 2(2 \cdot 2)\end{array}$ & $\begin{array}{r}0.4-12.0 \\
0 \cdot 2-12.0 \\
0 \cdot 8-10.0 \\
-0 \cdot 4-10 \cdot 0\end{array}$ & $\begin{array}{l}25 \cdot 6(1 \cdot 6)^{\star} \\
26 \cdot 2(1 \cdot 5)^{\star} \\
28 \cdot 2(2 \cdot 2)^{\star} \\
29 \cdot 2(1 \cdot 8)^{\star}\end{array}$ & $\begin{array}{l}20 \cdot 6(1 \cdot 6) \\
20 \cdot 4(1 \cdot 5) \\
20 \cdot 4(1 \cdot 8) \\
21 \cdot 8(2 \cdot 4)\end{array}$ & $\begin{array}{l}0 \cdot 1-10 \cdot 0 \\
1 \cdot 2-10 \cdot 0 \\
1 \cdot 8-14 \cdot 0 \\
1 \cdot 0-14 \cdot 0\end{array}$ \\
\hline
\end{tabular}

$\star 2 p<0.05$ compared with group 2 .

$+95 \%$ confidence intervals for the difference in mean values (unequal variance). 
Figure 1 Plasma concentrations of aortic and coronary sinus malondialdehyde during $M D A$, malondialdehyde; $H R$, heart rate. pacing. ${ }^{\star} 2 p<0.05$ compared with baseline.

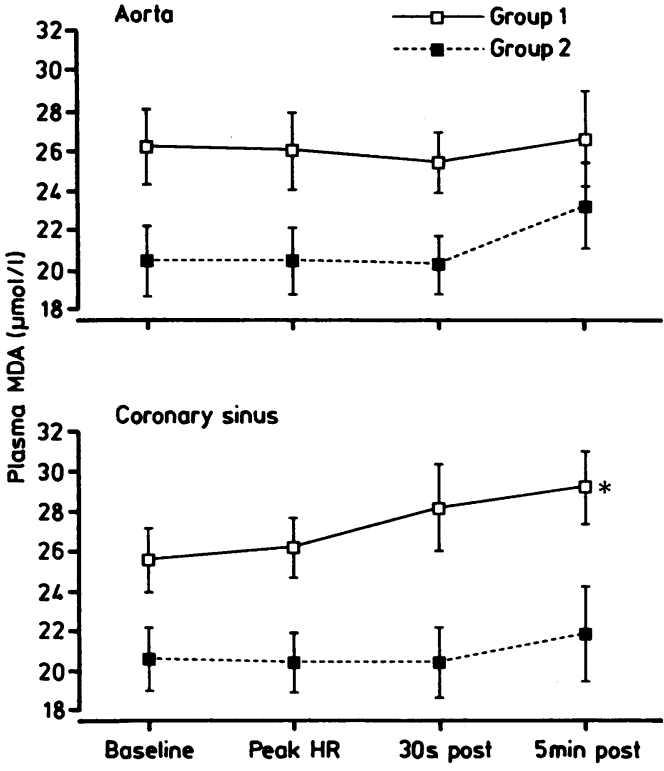

evidence of granulocyte activation as measured by aggregation after pacing induced ischaemia (unpublished observations). Reperfusion accelerates the production of oxygen derived free radicals by supplying a large substrate pool of molecular oxygen. The action of endothelial xanthine oxidase on purine metabolites accumulated during ischaemia is another possible system for generating radicals, ${ }^{1222}$ though its relevance has been questioned by workers who were unable to show significant xanthine oxidase activity in human myocardium. ${ }^{24} 25$ Whatever their source, these oxygen radicals peroxidise polyunsaturated membrane lipids, damaging their structure and function, a process which in itself generates further free radicals. ${ }^{6}$ Additionally, the activity of superoxide dismutase and glutathione peroxidase, two major mammalian intracellular radical scavengers, is reduced by hypoxia. ${ }^{26}{ }^{27}$ So free radical mediated cell damage is possible during any sequence of ischaemia/reperfusion and there is also at least some potential for autocatalysis/ self-perpetuation.

Malondialdehyde is one of many products of lipid peroxidation. The reaction between thiobarbituric acid and malondialdehyde produces a pink colour which can be measured by spectrophotometry. This assay has been used to study circulating lipoperoxides in many diseases. ${ }^{152829}$ The particular variation of the assay that we used gives higher values than those reported for other methods because it measures both pre-existing malondialdehyde plus whatever other substances give rise to malondialdehyde during the assay-that is in vitro and in vivo. ${ }^{15}$ In addition, several

Figure 2 Malondialdehyde extraction ratios during pacing. ${ }^{\star} 2 p<0.05$ compared with group 2. See legend to fig 1 for abbreviations. chemical species other than malondialdehyde can react with thiobarbituric acid to produce a pink to red colour. ${ }^{30}$ This relative lack of specificity has been criticised, but malondialdehyde does seem to be produced in relatively constant proportion to the rate of lipid peroxidation, ${ }^{31}$ and thus when all the samples from one patient are assayed simultaneously the results should reflect the degree of peroxidation at the time each sample was obtained.

We showed that patients with coronary artery disease who produce lactate across the myocardium during incremental cardiac pacing also show an increase in the coronary sinus concentration of malondialdehyde in the period immediately after pacing. These latter changes may develop as early as 30 seconds after pacing and persist for at least 5 minutes. They did not occur in patients who, irrespective of the presence of coronary artery disease, continued to extract lactate during incremental pacing. The time course of these changes is consistent with the hypothesis that intracardiac lipid peroxidation occurs even after brief periods of regional myocardial ischaemia, possibly as part of reoxygenation injury mediated by free radicals. For the technical reasons outlined above we may have underestimated the true degree of intra-myocardial lipid peroxidation.

The clinical relevance of the small though none the less statistically significant changes we did detect remains unclear. As indicated earlier, it has not been possible to show consistently the theoretically beneficial effects of radical scavenging interventions in animal models of myocardial ischaemia. ${ }^{2-8}$ Differences in the dosage and time course of administration of the agents used, and in the duration of occlusion/reperfusion may account for some of the variability in the results of these studies. In any case, the inability to modify ischaemic/ reperfusion damage with such interventions does not necessarily mean that free radicals are without pathogenetic significance. Indeed, lipid peroxides are known to be prothrombotic through effects on the coagulation system ${ }^{32}$ and platelets, ${ }^{33}$ and this could clearly have a role in coronary heart disease. ${ }^{34}$ Furthermore, the persistence of regional left ventricular dysfunction ("myocardial stunning") for several hours after brief ( $<20$ minutes) periods of coronary artery occlusion $^{35}$ and the same phenomenon after exercise induced and completely reversible myocardial ischaemia in dogs, ${ }^{36}$ may be the result of membrane lipid peroxidation mediated by free radicals. ${ }^{20}$ If this could be confirmed in humans, and the source of the free radicals identified, the way would be open for a thorough exploration of the potential therapeutic role of free radical scavenging agents and antioxidants in both acute and chronic ischaemic syndromes.

This study was supported by a British Heart Foundation grant.

1 Bolli R, Bharat SP, Jeroudi MO, Lai EK, McCay PB. Demonstration of free radical generation in "stunned" myocardium of intact dogs with the use of the spin trap $\alpha$-phenyl $N$-tert-butyl nitrone. J Clin Invest 1988;82:
476-85. 
2 Burrell CJ, Blake DR. Reactive oxygen metabolites and the human myocardium. Br Heart J 1989;61:4-8.

3 McCord JM. Oxygen-derived free radicals and reperfusion injury (pp 533-35). In: Cross CE, moderator. Oxygen radicals and human disease. Ann Intern Med 1987;107:526-45.

4 Jolly SR, Kane WJ, Bailie MB, Abrams GD, Lucchesi BR Canine myocardial reperfusion injury: its reduction by the combined administration of superoxide dismutase and catalase. Circ Res 1984;54:277-85.

5 Uraizee A, Reimer KA, Murray CE, Jennings RB. Failure of superoxide dismutase to limit size of myocardial infarction after $\mathbf{4 0}$ minutes of ischemia and 4 days of reperfusion in dogs. Circulation 1987;75:1237-48.

6 Werns SW, Shea MJ, Mitsos SE, et al. Reduction of the size of infarction by allopurinol in the ischemic-reperfused canine heart. Circulation 1986;73:518-24.

7 Reimer KA, Jennings RB. Failure of the xanthine oxidase inhibitor allopurinol to limit infarct size after ischemia and reperfusion in dogs. Circulation 1985;71:1069-75.

8 Ambrosio G, Weisfeldt ML, Jacobus WE, Flaherty JT. Evidence for a reversible oxygen radical-mediated component of reperfusion injury: reduction by recombinan human superoxide dismutase administered at the time of reflow. Circulation 1987;75:282-91.

9 Corr PB, Gross RW, Sobel BE. Amphipathic metabolites and membrane dysfunction in ischemic myocardium. Circ Res 1984;55:135-54.

10 Slater TF. Free radical mechanisms in tissue injury. Biochem $J$ 1984;222:1-15.

11 Knight JA, Smith SE, Kinder VE, Anstall HB. Reference intervals for plasma lipoperoxides: age-, sex-, and specimen-related variations. Clin Chem 1987;33:2289-91.

12 Dianzani MU. Biochemical effects of saturated and unsaturated aldehydes. In: McBrien DCH, Slater TF, eds. Free radicals, lipid peroxidation and cancer. London and New York: Academic Press, 1982:129-58.

13 Esterbauer $H$. Lipid peroxidation products: formation, chemical properties and biological activities. In: Poli $\mathrm{G}$ Cheeseman KV, Dianzani MU, Slater TF, eds. Fre radicals in liver injury. Oxford and Washington DC: IRI Press, 1987:29-47.

14 Herman MV, Elliot WC, Gorlin R. An electrocardiographic anatomic and metabolic study of zonal myocardial ischemia in coronary heart disease. Circulation 1967;35:834-46.

15 Santos MT, Valles J, Aznar J, Vilches J. Determination of plasma malondialdehyde-like material and its clinical application in stroke patients. J Clin Pathol 1980;33: applica.

16 Parker JO, West RO, Case RB, Chiong MA. Temporal relationships of myocardial lactate metabolism, left ventricular function and ST segment depression during ventricular function and ST segment depression during angina

17 Opie LH, Owen P, Riemersma RA. Relative rates of oxidation of glucose and free fatty acids by ischaemic and non ischaemic myocardium after coronary artery ligation in the dog. Eur J Clin Invest 1973;3:419-35.

18 Cobbe SM, Poole-Wilson PA. Continuous coronary sinus and arterial $\mathrm{pH}$ monitoring during pacing-induced ischaemia in coronary artery disease. $\mathrm{Br}$ Heart 1982;47:369-74.

1.9 Lewis DH, Del Maestro RF. Free radicals in medicine and biology. Acta Physiol Scand / Suppl / 1980;492:1-168.

20 Bolli R. Oxygen-derived free radicals and postischemic myocardial dysfunction ("stunned myocardium") $J$ Am Coll Cardiol 1988;12:239-49.

21 Jewett SL, Eddy LJ, Hochstein P. Is the autoxidation of catecholamines involved in ischemia-reperfusion injury? catecholamines involved in ischem
Free Radic Biol Med 1989;6:185-8.

22 Simpson PJ, Lucchesi BR. Free radicals and myocardial ischemia and reperfusion injury. $J$ Lab Clin Med 1987;110:13-30.

23 Rosson RD, Swain JL, Michael LH, Weakley S, Giannini E, Entman ML. Selective accumulation of the first component of complement and leukocytes in ischemic canine hear muscle. A possible initiatior of an extra-myocardia mechanism of ischemic injury. Circ Res 1985;57:119-30.

24 Downey JM, Hearse DJ, Yellon DM. The role of xanthine oxidase during myocardial ischaemia in several species including man. J Mol Cell Cardiol 1988;20(suppl II): 55-63.

25 Muxfeldt M, Schaper W. The activity of xanthine oxidase in heart of pigs, guinea pigs, rabbits, rats and humans. Basic Res Cardiol 1987;82:486-92.

26 Liu J, Simon LM, Philips JR, Robin ED. Superoxide dismutase in hyp

. Role of oxygen in uarnieri C, Flamigni the cellular damage induced by reoxygenation of

28 Aznar J, Santos MT, Valles J, Sala J. Serum malondialdehyde-like material (MDA-LM) in acute myocardial infarction. J Clin Pathol 1983;36:712-5.

29 Sato Y, Hotta N, Sakamoto N, Matsouka S, Ohishi N, Yag $\mathrm{K}$. Lipid peroxide levels in plasma of diabetic patients. Biochem Med 1979;21:104-7.

30 Knight JA, Pieper RK, McClellan L. Specificity of the thiobarbituric acid reaction: its use in studies of lipid peroxidation. Clin Chem 1988;34:2433-8.

31 Aust SD. Lipid peroxidation. In: Greenwauld RA, ed. CRC handbook of methods for oxygen radical research. London: CRC Press, 1985:203-7.

32 Barrowcliffe TW, Gutteridge JM, Gray E. Oxygen radicals, lipid peroxidation and the coagulation system. Agents Actions 1987;22:347-8.

33 Goto Y. Lipid peroxides as a cause of vascular disease. In: Yagi $\mathrm{K}$, ed. Lipid peroxides in biology and medicine. New York: Academic Press, 1982:295-303.

34 Stringer MD, Gorog PG, Freeman A, Kakkar VV. Lipid peroxides and atherosclerosis. Br Med J 1989;298:281-4. peroxides and acherosclerosis. Br. Med 1989;298:281 -4 Jr. Persistence of myocardial injury following brief periods of coronary occlusion. Cardiovasc Res 1976;10:678-86.

36 Homans DC, Sublett E, Dai XZ, Bache RB. Persistence of regional left ventricular dysfunction after exerciseregional left ventricular dysfunction after exercise-
induced myocardial ischaemia. J Clin Invest 1986;77: induced 